\title{
Evaluation of sustainable tourism practices in the state of Bihar, India
}

\author{
Ajit Kumar Singh, Dr. Pankaj Kumar Tyagi, and Priyanka Tyagi \\ Chandigarh University, Punjab, India
}

\begin{abstract}
The impact of tourism on the local community and environment has raised the concern of the sustainability of tourist destinations. Therefore, in the year 1998, the World Tourism Organization (WTO) [1] enriched the concept of sustainable tourism by defining it as " tourism development that can meet the demand of both tourists and host communities while preserving, and improving the opportunity for future development ". This paper tends to explore the current condition of sustainable tourism in Bihar. Primary data are collected from the ten major tourist destinations of the state, i.e., Patna, Gaya, Bodhgaya, Rajgir, Nalanda, Raxaul, Munger, Vaishali, Muzaffarpur, and Bhagalpur. The finding of this paper supports that sustainable practices at tourist places of Bihar are not significantly full fill the tourist expectations. Also, most people think that the state government is not taking the necessary steps and initiatives for the sustainable development of tourism in Bihar. This research paper's findings help tourism stakeholders understand the current conditions of sustainable tourism in the state and help them reframe their policies and strategies for the overall development of the tourism sector.
\end{abstract}

\section{Introduction}

Bihar is known for its religious sites and its ancient civilization. This state offers a vast option to the tourists in terms of historical monuments, cultural diversities, antiques and artifacts, architecture, festivals and fairs, yoga, and eco-tourism. Looking at the prospect of tourism in the state, the government has started taking interest in this sector and taken many initiatives in this field. Therefore, the impact of tourism on the local community and environment must be analyzed, and a sustainable approach should be adopted for the betterment of the tourist destination. In this regard, various government policies, seminars, and multi-level conferences have been proposed to promote sustainable tourism. According to Beaumont, people with eco-awareness travel more frequently than others, and therefore they become a significant target audience for the tourism industry [2].

The present study is conducted in order to full fill the following objectives:

$>$ To examine tourist's perception of sustainable practices at tourist places of Bihar.

To examine state government initiatives for the development of Bihar as a sustainable tourism destination.

Sustainable development is defined as a quality-of-life approach without destroying future resources. Various authors have defined sustainable development such as green chemistry, clean production, pollution level, degradation of resources etc. The decision on 
tourism is influenced both by the community and the government. The development of sustainability is recognized as critical for community welfare. With the assistance of the United Nations, the Rio summit popularised sustainability development by adopting an 'indicator of sustainable development.' The United Nations tends to develop sustainable development goals with the world leaders to aim 169 countries as their target where the countries are working economically, culturally, and environmentally. They proposed 17 Sustainable development goals (SDSs) for the betterment of society. Experts claim that smartness leads to sustainability, where smartness analyses the possibility for tourist destination sustainability. Sustainable development in tourism is defined in various ways by various authors [3]. The importance of sustainability excites the people to aim towards sustainability, resulting in the quality of life at their respective destinations. People at their respective destinations play a significant role towards sustainability as a result of successful business and their well-being [4]. Bihar is one such example where people face accommodation, amenities, and attraction, where it recommends moving towards an ecological balance and a sustainable location. Tourists' decisions are influenced by community involvement. However, instead it is a half-truth that the decision made by the tourist involves the working of the government towards tourism which increases the visitation and the majority of the cost linked to tourism [5]. The Bihar government has been promoting Bihar tourism since 1982, where it has been noticed that with the coming of the government inaction, tourism has led to exponential growth [6]. Still, some people questioned sustainable development when the United Nations introduced "indicators to measure sustainability," which was highly popularised by the Rio Summit as Rio de Janeiro Earth Summit held in [7]. Various assumptions were set for indicators for sustainability assessment as "multidimensional"[8]. However, soon later, it was portrayed as competitiveness and a role of indicator for tourism destinations [9].

Journal of Sustainable Tourism' mentioned the issues faced for sustainable tourism: social, economic, environmental, governance, and cultural dimensions [10]. Eventually, mentioning the businesses' hardship and success, changing consumer behavior towards pursuing sustainable goals [11]. Therefore, Sustainable development goals were set up with the United Nations' help by 25 September 2015, stating 17 goals and 169 targets as a nation where economic growth, environmental protection, and social inclusion are embraced [12]. Nowadays, Sustainable development is considered the path of smartness where smartness is considered a possibility to accomplish sustainability at their destination [13]. Therefore, sustainable tourism has taken an increasingly prominent position in theentire market [14].

\section{Results, and Discussion}

\subsection{Sampling and data attainment}

The research is descriptive cum quantitative and is based on primary data of tourists who visited different tourist destinations of Bihar. For data analysis,IBM- SPSS Version 20 and IBM - AMOS Version 20 is used.For primary data, a questionnaire is prepared wherein the 5 point rating Likert scale is used.Data was collected through a convenient sampling method between 11 December to 21 December 2020.The literature review resulted in the generation of the initial pool of 22 suitable items. Items were assessed for the validity of content through two separate panels.Based on comments given by the panel, four items were not included in the pool of items which resulted in a total of 18 items. We have collected our first sample, and the items were assessed for content validity. Secondly, we have performed exploratory factor analysis (EFA) and reliability tests. In the third phase, Confirmatory Factor Analysis (CFA) and validating test were conducted for the other sample to finalize the measurement 
model. To measure the sample size adequacy, the appropriateness of the Exploratory Factor Analysis (EFA), Kaiser Mayer- Olkin (KMO) [15], and the Bartlett's test of sphericity were performed. The result shows that the KMO value is .937 and Bartlett's test of sphericity is .00 , which shows sampling adequacy for our research study, and a significant relationship between our variables. The respondent's profilesare shown in Table 1.

Table 1. Profile of Participants - Sample One and Two.

\begin{tabular}{lcc}
\multicolumn{1}{c}{ VARIABLES } & Sample One (n= 202) & Sample Two (n= 202) \\
\hline \multicolumn{1}{c}{ Gender } & 158 & 138 \\
Male & 44 & 64 \\
Female & & \\
\multicolumn{1}{c}{ Age } & 172 & 128 \\
$18-25$ & 18 & 29 \\
$26-35$ & 6 & 14 \\
$36-45$ & 6 & 31 \\
Above 45 & & \\
Educational Qualification & 156 & 139 \\
Undergraduate & 22 & 35 \\
Graduate & 18 & 23 \\
Post Graduate & 6 & 5 \\
Doctoral degree and above & & \\
$\quad$ Occupation & 20 & 74 \\
Service & 14 & 29 \\
Business & 7 & 32 \\
Self employed & 161 & 67 \\
Other & & \\
$\quad$ Total Annual Income & 135 & 98 \\
Less than 250000 & 33 & 63 \\
Rs 250001 - 500000 & 11 & 24 \\
Rs 500001- 1000000 & 23 & 17 \\
More than Rs 1000000 & & 196 \\
$\quad$ Nationality & 198 & 6 \\
Indian & 4 & \\
Other than Indian & & \\
\hline
\end{tabular}

\subsection{Methods and analysis of data for the first objective}

The first objective is to examine tourist's perception of sustainable practices at tourist places of Bihar. To achieve this objective we have formulated two hypothesis. The first hypothesis statement is tourist's perception of sustainable practices at tourist places of Bihar is good. Respondents are asked " Did sustainable practices at tourist places of Bihar meet your expectation during your trip?", and their perceptions are recorded in a Likert five point scale ( $1=$ Strongly disagree , $2=$ Disagree, $3=$ Undecided, $4=$ Agree , $5=$ Strongly agree ).

To achieve our hypothesis, we have formulated given below null and alternate hypothesis:

$>$ Ho: $\mu=3.05$

$>$ Ha: $\mu \neq 3.05$

Our data do not follow a normal distribution;therefore we have used a non-parametric test i.e., One sample Wilcoxon Signed Rank statistics to test our null hypothesis. The test is conducted on a sample of 202 respondents and at 0.05 significance level. Test result shown in Table 2, and Figure 1 depicts that, the P value is 0.149 , which is more than .05 . Thus, our null hypothesis is retained. Test result concludes that respondents perception of sustainable practices at tourist places of Bihar is not significantly full fill their expectations as the median response lies near to 3.0 
Table 2. One sample Wilcoxon Signed Rank Test statistics.

\begin{tabular}{|c|c|c|c|c|}
\hline \multicolumn{5}{|c|}{ Hypothesis Test Summary } \\
\hline & Null Hypothesis & Test & Sig. & Decision \\
\hline & $\begin{array}{l}\text { The median of Tourist expectation on } \\
\text { sustainable practices at tourist places of } \\
\text { Biharequals } 3.05 \text {. }\end{array}$ & $\begin{array}{l}\text { One-Sample } \\
\text { Wilcoxon Signed } \\
\text { Rank Test }\end{array}$ & .149 & $\begin{array}{l}\text { Retain the null } \\
\text { hypothesis. }\end{array}$ \\
\hline
\end{tabular}

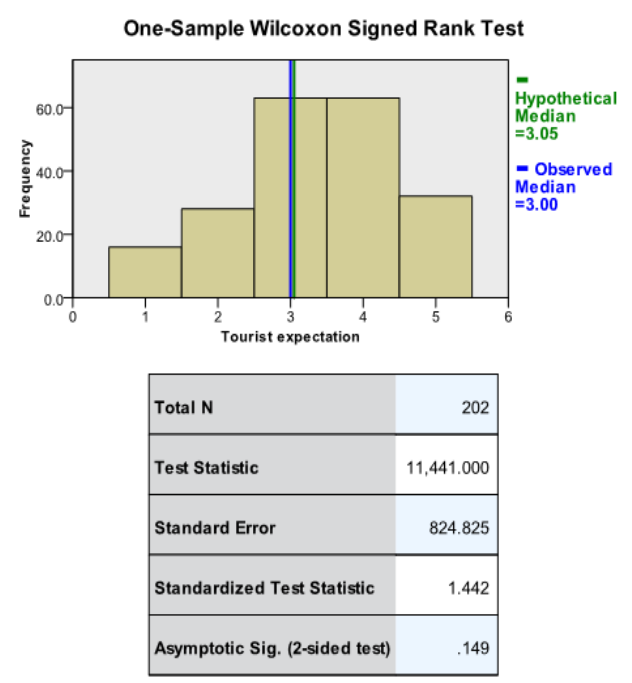

Fig. 1. Hypothetical and Observed Median of One Sample Wilcoxon Statistics.

The second hypothesis statement is tourist's perception on the advertisement and promotion of sustainable development of tourism in Bihar is good. Respondents are asked " How often you see promotional material or advertisement of sustainable tourism in Bihar ?" and their perceptions are recorded in a Likert five point scale ( $1=$ Not at all , $2=$ Not really, 3 = Undecided, $4=$ Some what, $5=$ Very much) .

To achieve our hypothesis, we have formulated given below null and alternate hypothesis:

$>$ Ho: $\mu=2.50$

$>$ Ha: $\mu \neq 2.50$

Data do not follow normal distribution therefore, One sample Wilcoxon Signed Rank statistics are used to test our null hypothesis. Test is conducted on a sample size of 202 respondents and at 0.05 significance level. Test result shown in Table 3 and Figure 2 depicts that, $\mathrm{P}$ value is 0.568 which is more than .05 . Thus, our null hypothesis is retained. Test result concludes that our respondents have not seen promotional material or advertising of sustainable tourism of Bihar tourism to a large extent as the median value is only 2.50 .

Table 3. One sample Wilcoxon Signed Rank Test statistics.

\begin{tabular}{|c|c|c|c|c|}
\hline \multicolumn{5}{|c|}{ Hypothesis Test Summary } \\
\hline & Null Hypothesis & Test & Sig. & Decision \\
\hline 1 & $\begin{array}{l}\text { The median of Promotion or advertising of } \\
\text { Sustainable Tourism in Bihar equals } 2.50 \text {. }\end{array}$ & $\begin{array}{l}\text { One-Sample Wilcoxon } \\
\text { Signed Rank Test }\end{array}$ & .568 & $\begin{array}{l}\text { Retain the null } \\
\text { hypothesis. }\end{array}$ \\
\hline
\end{tabular}




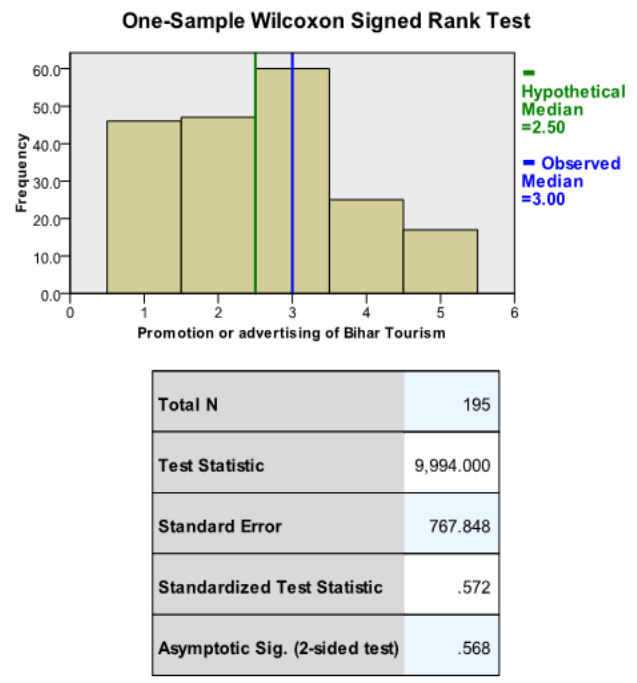

Fig. 2: Hypothetical and Observed Median of One sample Wilcoxon Statistics.

\subsection{Methods and analysis of data for the second objective}

The second objective is to examine state government initiatives for the development of Bihar as a sustainable tourism destination. The hypothesis statement is that tourists' perception of state government initiatives for sustainable tourism development in Bihar is good. Respondents are asked " Do you think state government is taking necessary steps and initiatives for the sustainable development of Tourism in Bihar?" and their perceptions are recorded in a Likert five point scale $(1=$ Not at all, $2=$ Not really, $3=$ Undecided, $4=$ Some what, 5 = Very much).

To achieve our hypothesis, we have formulated given below null and alternate hypothesis:

$>$ Ho: $. \mu=2.75$

$>\mathrm{Ha}: \mu \neq 2.75$

One sample Wilcoxon Signed Rank statistics is used to test our null hypothesis as our data is not normally distributed. The test is conducted on a sample of 202 respondents and at 0.05 significance level. The test result shown in Table 4 and Figure 3 depicts that, $\mathrm{P}$-value is 0.433 , which is more than .05 . Thus, our null hypothesis is retained. Test result concludes that most of the respondents think state government is not taking significant steps and initiatives for the sustainable development of Tourism in Bihar as the median value lies between 2 and 3 .

Table 4. One sample Wilcoxon Signed Rank Test statistics.

\begin{tabular}{|c|c|c|c|c|}
\hline \multicolumn{5}{|c|}{ Hypothesis Test Summary } \\
\hline & Null Hypothesis & Test & Sig. & Decision \\
\hline & $\begin{array}{l}\text { The median of State government initiatives for } \\
\text { the sustainable development of tourism in } \\
\text { Bihar. equals } 2.75 \text {. }\end{array}$ & $\begin{array}{l}\text { One-Sample } \\
\text { Wilcoxon Signed } \\
\text { Rank Test }\end{array}$ & .433 & $\begin{array}{l}\text { Retain the null } \\
\text { hypothesis. }\end{array}$ \\
\hline
\end{tabular}




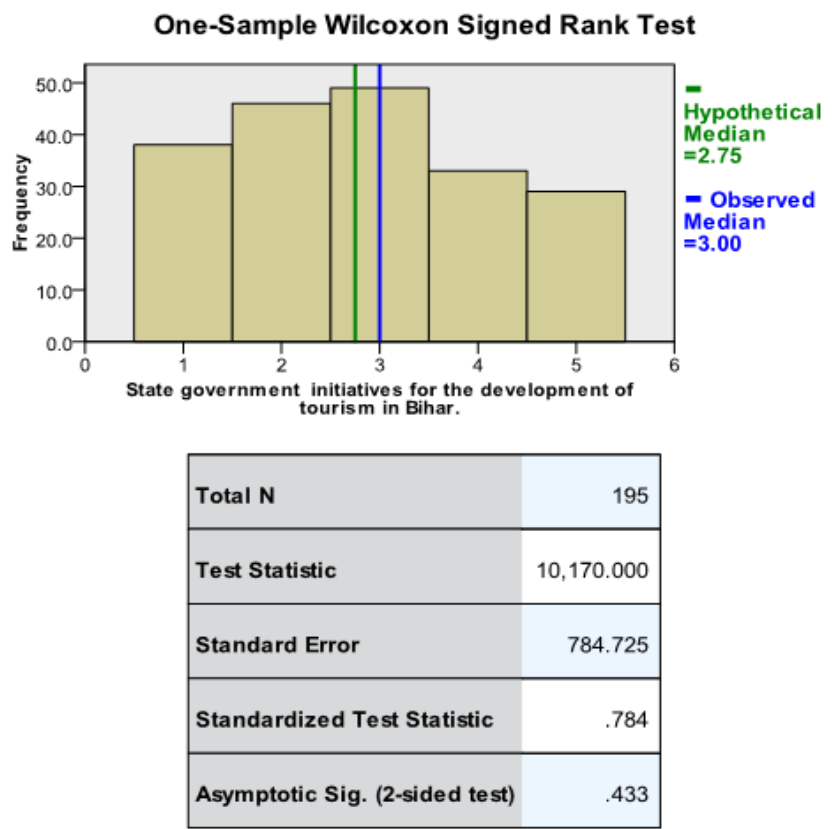

Fig. 3. Hypothetical and Observed Median of One sample Wilcoxon Statistics.

\section{Conclusions}

1. Research on sustainability is gaining more attention in recent years. Sustainable tourism is limited to the appropriate utilization of natural resources and linked to social, cultural, and economic sustainability. Researchers worldwide have made efforts to address issues emerging in their respective tourist destinations.

2. The findings from these studies have significantly contributed to both theoretical and managerial implications for sustainable tourism. The present study explores the current condition of sustainable tourism in Bihar. The study depicts that tourist's perception of sustainable practices at Bihar tourist places is not significantly full fill their expectations.

3. Respondents have also not seen promotional material or advertisements of sustainable tourism significantly. Thus, the importance of sustainable tourism and its practices needs to be promoted across the state through different dimensions of advertisement and promotions.

4. Also, most people think that the state government is not taking the necessary steps and initiatives for the sustainable development of tourism in Bihar. Hence, the government needs to reframe its existing tourism policy and should allocate significant space to sustainability.

5. Bihar has enormous potential for the tourism industry, directly or indirectly benefiting all other primary, secondary, and tertiary industries. However, due to poor infrastructure, lack of awareness, lack of political will, and bad governance, this industry is not flourishing to its fullest extent.

6. The study has implications for the tourism industry stakeholders in providing insights into the unaddressed challenges of the state tourism industry. The study may significantly help the tourism sector to develop and adopt the best strategies for the overall development of Bihar tourism. 


\section{References}

1. World Tourism Organization. Guide for Local Authorities on Developing Sustainable Tourism, 9 (WTO: Madrid,Spain, 1998)

2. N. Beaumont, J. Ecotourism, 10, 135 (2011)

3. P. Glavič, A Multi-Criterion Framework (2006)

4. V. Mathew, Impact of responsible tourism on destination sustainability and community quality in tourism destinations (2001)

5. Joppe, Sustainable community tourism development revisited (1999)

6. Rahman, Marketing of Bihar Tourism-A Buddhist Destination Transforming to Leisure Destination (2012)

7. S. Bell, Sustainability Indicators: Measuring the Immeasurable? (1999)

8. Munda, A Multi-Criterion Framework.Environment, Development and Sustainability, 7, 117 (2005)

9. M. Cucculelli, Evidence from Italian Destinations of Excellence (2016)

10. B. Bramwell, Journal of Sustainable Tourism: looking back and moving forward (2016)

11. Xavier Font, Sustainability and marketing in tourism: its contexts, paradoxes, approaches, challenges and potential (2017)

12. M. Stafford-Smith, Sustainability Science, 12, 911 (2017)

13. J. F. Perles-Ribes, The Pathway from Smartness to Sustainability (2021)

14. E. Butzmann, H. Job, J. Sustain. Tour., 25, 1736 (2017)

15. H. F. Kaiser, Psychometrika (1970) 